\author{
Military Technical College \\ Kobry El-Kobbah, \\ Cairo, Egypt
}

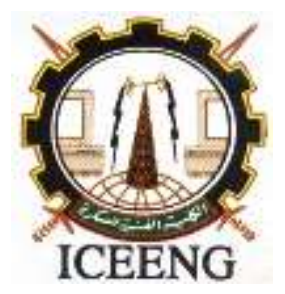

\author{
$11^{\text {th }}$ International Conference \\ on Electrical Engineering \\ ICEENG 2018
}

\title{
PERFORMANCE ANALYSIS OF PONS TOPOLOGIES
}

M. D. Hussien *, A. A. Mohamed ${ }^{\star}$, M. I. Hosni*, A. M. Mokhtar**, M. M.Youssef*, and K. M. Hassan**

\section{ABSTRACT}

In this paper a performance analysis of passive optical networks (PONs) topologies is proposed. A powerful software design tool "OptiSystem" is used to analyze the performance and compare between two types of PONs topologies which are tree or star topology and bus topology. The performance analysis and comparison is performed in terms of communication distance, Q-factor, and bit error rate (BER) for each network topology. The proposed results are important to determine the maximum communication distances that can be reached by each topology with certain network parameters.

\section{KEY WORDS}

PON, Tree topology, Star topology, Bus topology

* Egyptian Armed Forces.

** Electrical engineering Dept., FUE, Cairo, Egypt. 


\section{Introduction}

PONs are the principal networks for the broadband access Networks which are also fiber access network, they are called passive networks as they don't use any active electrically powered equipment like that used in the active optical networks (AON) (Ethernet switch), instead they only use passive components such as splitters, couplers, or filters $[1,2]$. PONs are used to provide customers with multimedia services (internet - TV - VOIP phone - internet services) with high data rate and through a network which is low cost and easy to implement [3]. PONs architectures are based on main components which are an optical line terminal (OLT), optical distribution network (ODN), and optical network units (ONUs) as shown in Fig.1 [3]. It can be configured into different topologies as (Tree-Tree with redundant trunk - bus - ring) topology with different distances between nodes, physical interconnections, and transmission power. Each topology has its advantages and drawbacks, which will dedicate the type of the used application in each network [4].

\section{PONs Topologies}

\subsection{Tree Topology}

It is the most commonly used topology in PONs and generally it is known as a star topology. In this topology, a single fiber is connected from OLT to splitter, and from the splitter there is a fiber link connected to each ONU as shown in Fig 2 [5-7].The main advantages of this topology is that there is only a single splitting point which is useful for easy and simple failure detection, and the signal power is divided equally through the ONUs due to the broadcasting transmitting technique which leads to share cost between ONUs. However, the main disadvantages are the low reliability, because failure in link between OLT and splitter is considered as fatal failure as it affects the whole communication network. Another drawback is the limiting number of ONUs due to the splitting loss [5].

\subsection{Tree with Redundant Trunk}

The construction of this topology is the same as the tree topology but with two fiber links connected with OLT for redundancy as shown in Fig. 3, as both fibers are connected by separate trunks to avoid the fatal failure of cutting the fiber link connected with OLT $[5,7]$. But this will require more fiber deployment and more complex access protocol [5].

\subsection{Bus Topology}

In this topology, a single fiber link is extended from OLT and contains several tap couplers each one of them is connected to one of the ONUs as shown in Fig. 4. The main advantages of this topology are the ability to use minimal amount of optical fiber (if there is directly connection between ONUs and couplers), and it is easy to add new ONU by adding new tap coupler for connection. However the drawbacks are the fatal failure for the single link (as the tree topology), and the degradation of signal along the fiber due to the losses in the tap couplers which makes far ONUs receive very weak signal [5]. The expression for the losses between OLT and the first ONU can be defined as the ratio between the transmitted power from OLT (POLT) and the received power to the first ONU (PONU1) and is given by [8] : 
$10 \log \left(\mathrm{POLT} / \mathrm{PONU}_{1}\right)=\alpha \mathrm{L}+\mathrm{L}_{\mathrm{tap}}+2 \mathrm{~L}_{\mathrm{c}}+\mathrm{L}_{\mathrm{i}}$

in which $\alpha$ is the attenuation factor, $L$ is length between OLT and the ONU, $L$ tap is the Tap loss, $L_{c}$ is the connector loss, and the intrinsic loss of the coupler is $L_{i}$. However, to determine the losses between the OLT and the $\mathrm{N}^{\text {th }}$ ONU, the previous formula is used with adding the throughput loss ( $L_{\text {thru }}$ ) which is the result of the unused transmission port of the intermediate couplers, and this will be defined according to the following formula [8]:

$10 \log \left(\mathrm{POLT} / \mathrm{PONU}_{\mathrm{N}}\right)=\alpha \mathrm{L}_{\text {tot }}+\mathrm{L}_{\text {tap }}+2 \mathrm{NL}_{\mathrm{c}}+\mathrm{NL}_{\mathrm{i}}+(\mathrm{N}-1) \mathrm{L}_{\text {thru }}$

\subsection{Ring Topology}

It is mainly used in metropolitan networks. There are two ways to reach OLT for redundancy in case of a fiber cut as shown in Fig. 5 [5, 7, 9]. But this will require complex devices in ONUs for processing the signal in both directions, also it has the same problem of degradation of optical signal when passing through ONUs as the bus topology which will restrict the number of ONUs [5].For this reasons we will focus in our study on the tree and bus topologies.

\section{Simulation Results and Analysis}

Optisystem7 was used to perform a performance analysis of the tree and bus topologies of PONs, consequently a comparison is proposed between tree or star topology using splitter, and a bus topology using couplers in terms of distance, BER and Q factor. Based on standard of ITU-T G.984.x [10], GPON is simulated using the network parameters shown in Table 1.

Table 1 Simulation parameters for the investigated networks

\begin{tabular}{|c|c|c|}
\hline Components & Downstream & Upstream \\
\hline Bitrate & $2.5 \mathrm{~Gb} / \mathrm{s}$ & $1.25 \mathrm{~Gb} / \mathrm{s}$ \\
\hline Coding mode & NRZ & NRZ \\
\hline $\begin{array}{r}\text { Laser source (Wave } \\
\text { length) }\end{array}$ & $\begin{array}{r}1490 \mathrm{~nm} \text { (voice and data) } \\
1550 \text { (video) }\end{array}$ & $1310 \mathrm{~nm}$ \\
\hline $\begin{array}{r}\text { Laser source } \\
\text { (transmitted power) }\end{array}$ & $3 \mathrm{dBm}$ & $2 \mathrm{dBm}$ \\
\hline Fiber Distance & & \\
\hline Power Splitter & & \\
\hline Photodetector (Type) & PIN & PIN \\
\hline
\end{tabular}

GPON consists of main components, as in the transmitter section in Fig.6, there are continuous wave laser acts as an optical source, pseudo random bit sequence generator (PRBS) that determines the data rate, NRZ modulator which is the modulation method and Mach-Zehnder Modulator which is used to control the amplitude of the optical wave. In the receiver section as shown in Fig.7, Bessel Filter is a shaping feature used to preserve the shape of the pass band signal, PIN Photodiode is used to convert optical signal into electrical signal, Low pass filter is used to cut the high Bessel frequencies, Optical Regenerator 3R is connected to BER analyzer to show the eye diagram and make performance analysis of the received signal in terms of quality and bit error rate. For the used optical fiber, we used OptiFiber program and connected it with the Optisystem to determine the attenuation $(0.362 \mathrm{~dB} /$ $\mathrm{Km}$ for $1310 \mathrm{~nm}-0.216 \mathrm{~dB} / \mathrm{Km}$ for $1490 \mathrm{~nm}$ ), dispersion $0.401 \mathrm{ps} / \mathrm{Km} . \mathrm{nm}$ for 1310 
$\mathrm{nm}-13.321 \mathrm{ps} / \mathrm{Km} . \mathrm{nm}$ for $1490 \mathrm{~nm})$, and nonlinear refractive index $\left(\mathrm{n}_{2}\right)$ according to Kerr effect $\left(2.607 \mathrm{e}^{-20} \mathrm{~m}^{2} / \mathrm{W}\right.$ for $1310 \mathrm{~nm}-2.51 \mathrm{e}^{-20} \mathrm{~m}^{2} / \mathrm{W}$ for $1490 \mathrm{~nm}$ ) in the fiber as a function of wavelength. In Fig.8, the transmitter in the tree or star topology of GPON transmits signal towards a fiber which is connected to a passive splitter with ratio 1:8 used to distribute and divide the signal towards 8 ONUs. In the investigated tree topology GPON, the BER of the downstream at the 8 ONUs is $3.42 \times 10^{-22}$ and the Q factor is 9.61 as shown in Fig. 9 which is an acceptable results compared to the results of BER $1.24 \times 10^{-21}$ in [11].

Fig. 10 shows the structure of the investigated bus topology GPON that consists of 8 ONUs connected to a fiber link using a coupler for each ONU connection. We studied the effect of changing the coupling coefficient $(30: 70,20: 80,10: 90)$ and additional losses $(1.9 \mathrm{dBm}, 1.3 \mathrm{dBm}, 0.75 \mathrm{dBm})$ respectively, and with distance $2.5 \mathrm{Km}$ between two consecutive ONUs on which the first ONU is at $2.5 \mathrm{Km}$ from the OLT transmitter and the last 8th ONU is far from the OLT transmitter by $20 \mathrm{Km}$. Knowing that the acceptable BER is $10^{-10}$, it is concluded that using a coupler of ratio 30:70 the farthest ONU with an acceptable results is the third ONU with $\mathrm{Q}$ factor 10.75 and BER of $2.73 \times 10^{-27}$ as shown in Fig. 11, however the fourth ONU has Q factor 4.31 and BER 8.037 $\times 10^{-6}$ which is not acceptable as shown in Fig.12. If the used coupler of ratio 20:80 the farthest ONU with an acceptable results is the fourth ONU with Q factor 7.31 and BER $1.225 \times 10^{-13}$ as shown in Fig.13, while the fifth ONU has Q factor 3.94 and BER $8.02 \times 10^{-5}$ as shown in Fig.14. In coupler of ratio 10:90, the fifth ONU got an acceptable results as it has Q factor 6.21 and BER $2.6 \times 10^{-10}$ as shown in Fig.15, however the sixth ONU has Q factor 3.81 and BER $6.76 \times 10^{-5}$ as shown in Fig.16. Table 2 summarizes the simulation results from the proposed comparison between tree and bus network topology.

Table 2 Summary of the proposed simulation results

\begin{tabular}{|r|c||c|c|c|}
\hline \multicolumn{1}{|c|}{} & \multicolumn{1}{c||}{$\begin{array}{c}\text { Tree } \\
\text { topology }\end{array}$} & \multicolumn{3}{c|}{ Bus topology } \\
\cline { 2 - 5 } \multicolumn{1}{|c|}{ Passive device } & Splitter & \multicolumn{3}{c|}{ Coupler } \\
\hline Ratio & $1: 8$ & $30: 70$ & $20: 80$ & $10: 90$ \\
\hline $\begin{array}{r}\text { Communication } \\
\text { Distance }\end{array}$ & $20 \mathrm{Km}$ & $7.5 \mathrm{Km}$ & $10 \mathrm{Km}$ \\
\hline BER & $3.42 \times 10^{-22}$ & $2.73 \times 10^{-27}$ & $\begin{array}{c}1.225 \times 10^{-} \\
13\end{array}$ & $2.6 \times 10^{-10}$ \\
\hline
\end{tabular}

\section{CONCLUSION}

It is concluded that there is a great gap in losses between the tree / star topology and the bus topology. Our investigation regarding PON tree topology shows that the loss is approximately constant for all 8 ONUs and this appeared by measuring the BER of 8 ONUs and found that all of them are $3.42 \times 10^{-22}$. However in the bus topology, losses are linearly increased based on coupling coefficient, distances and number of users. The proposed simulation results regarding PON bus topology with $2.5 \mathrm{Km}$ between ONUs and with coupling coefficient (30:70, 20:80, 10:90), shows that the farthest ONUs that can get acceptable results are the third, fourth, fifth ONU, respectively. 


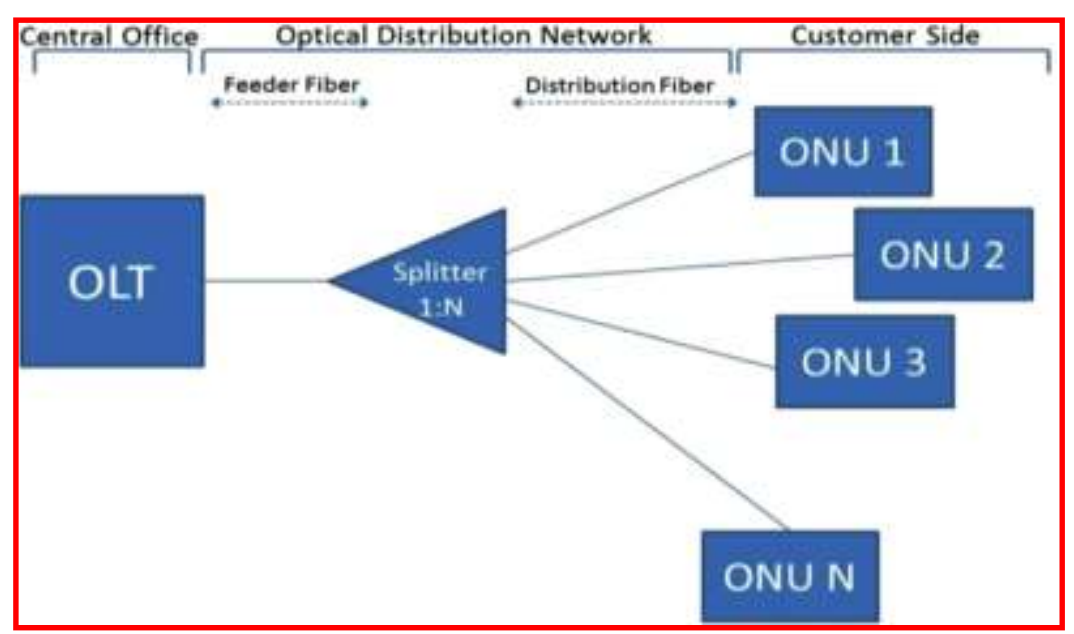

Fig.1. PON's Architecture [3].

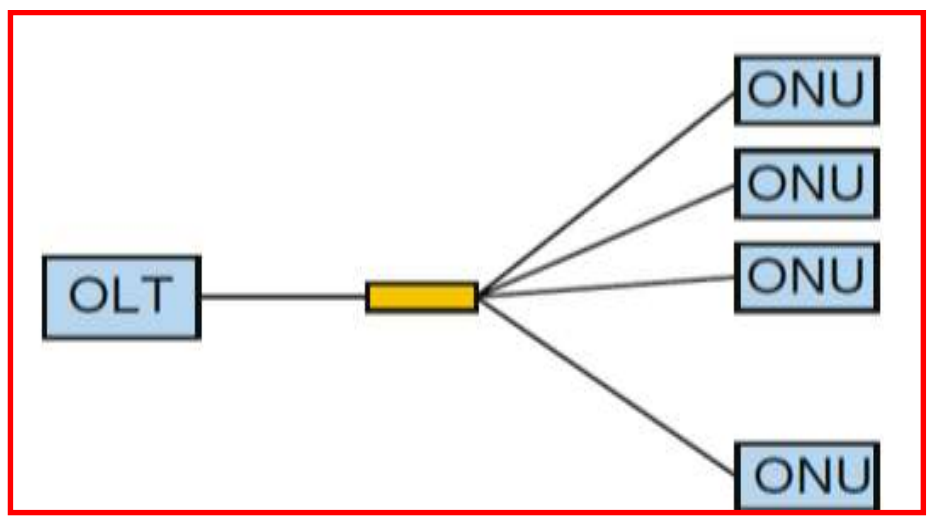

Fig.2. Tree topology (1:N splitter) [5].

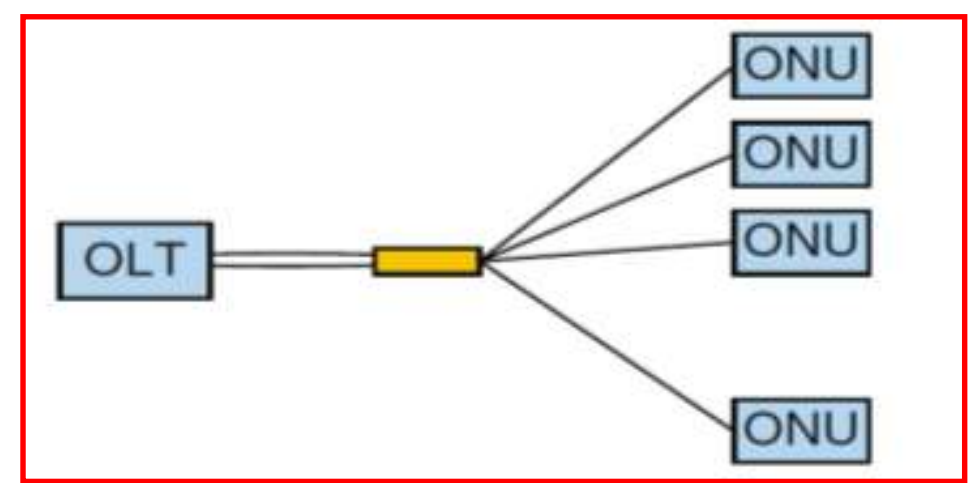

Fig.3. Tree with Redundant Trunk [5]. 


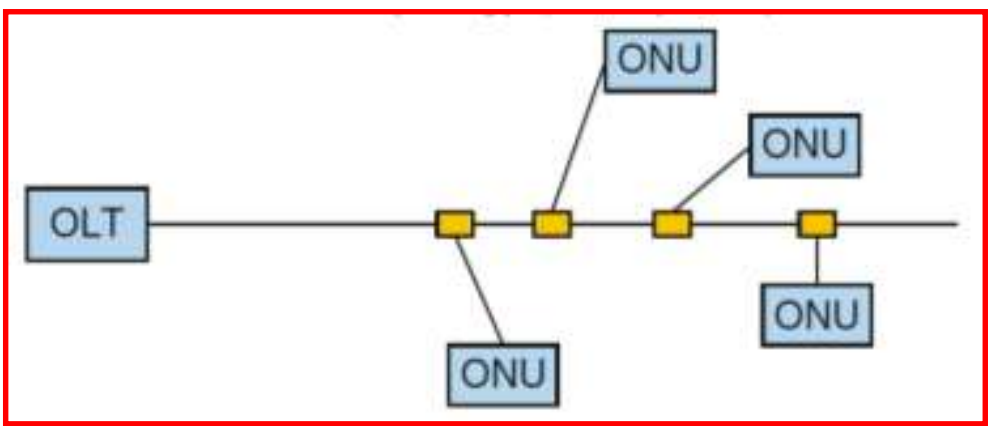

Fig.4. Bus Topology [5].

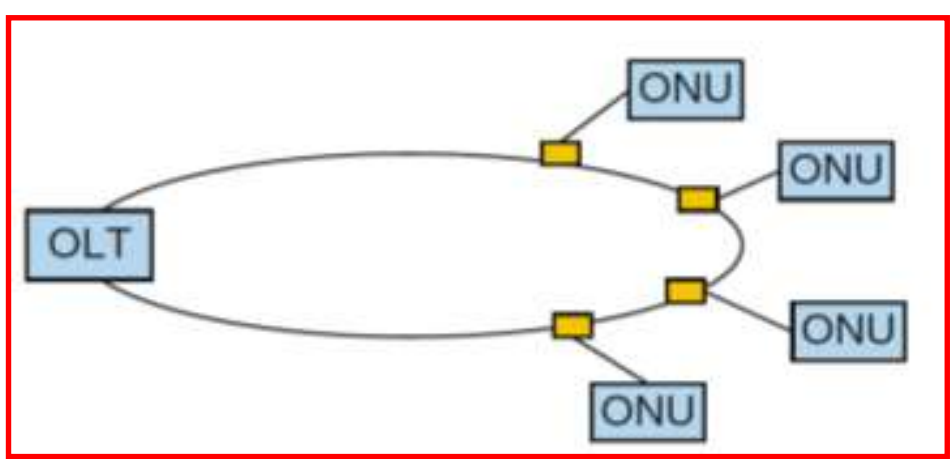

Fig.5. Ring Topology [5].

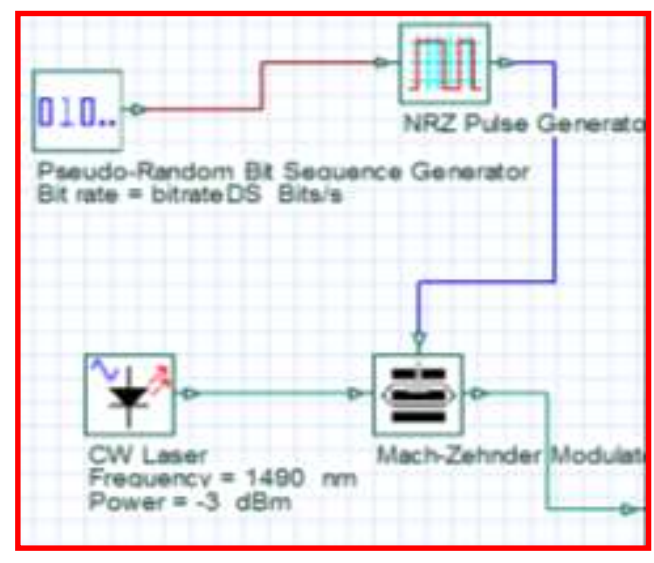

Fig.6. Structure of the transmitter.

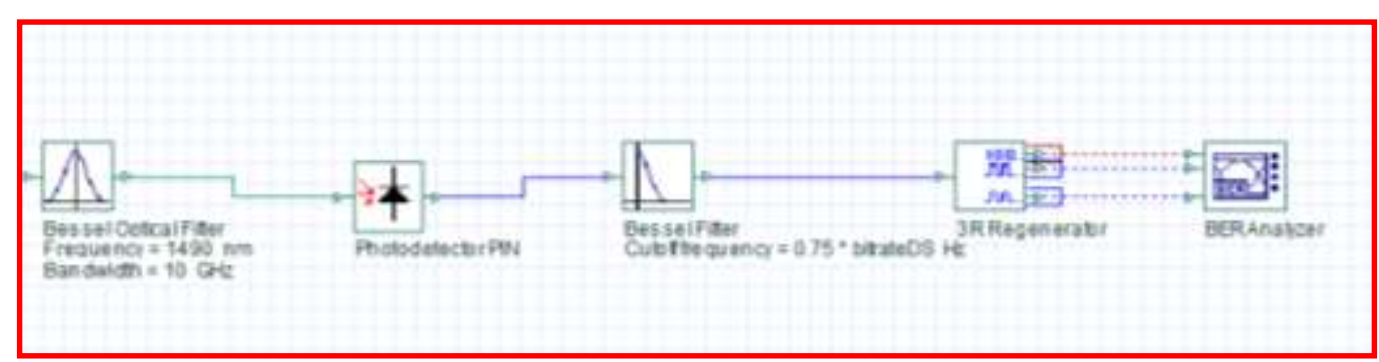

Fig.7.Structure of the receiver. 


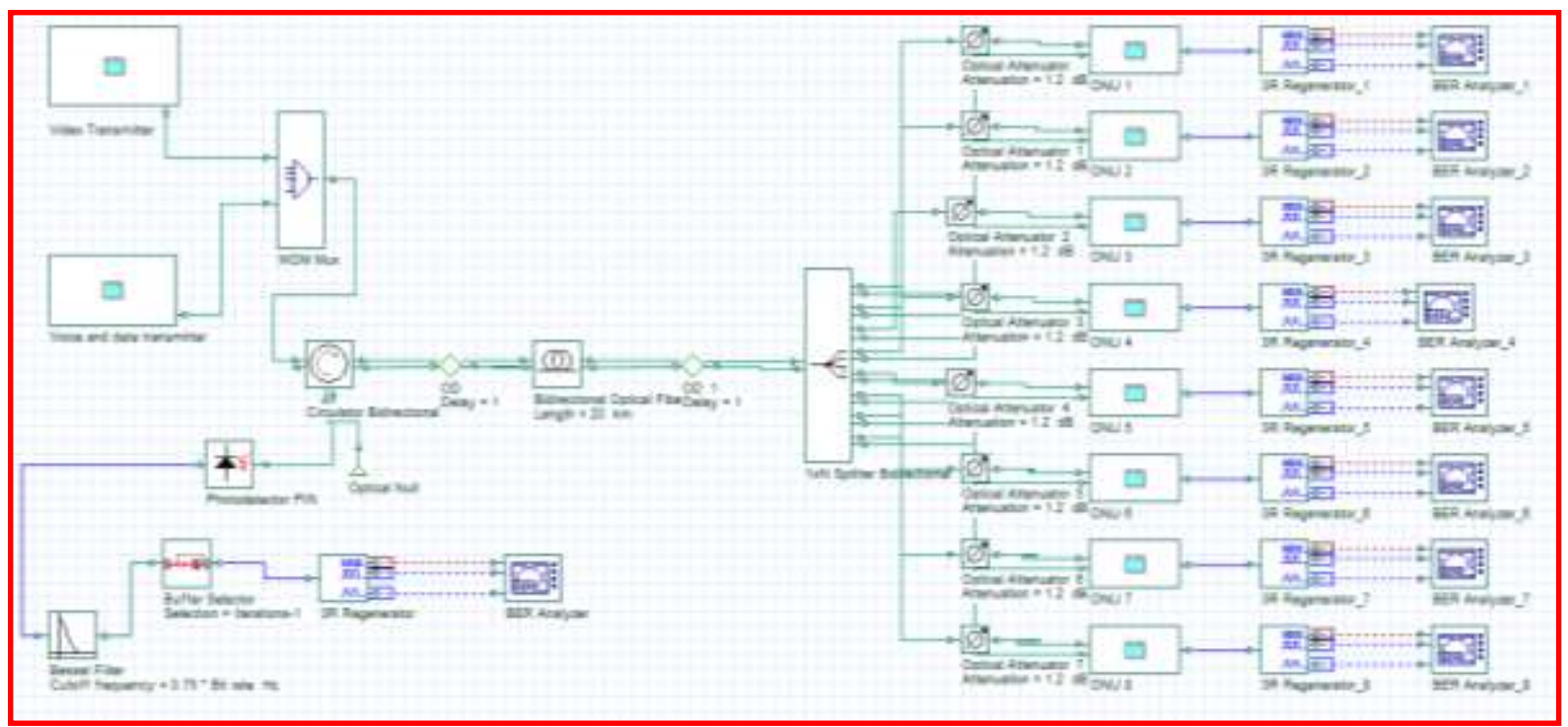

Fig.8.Structure of the investigated tree topology of GPON

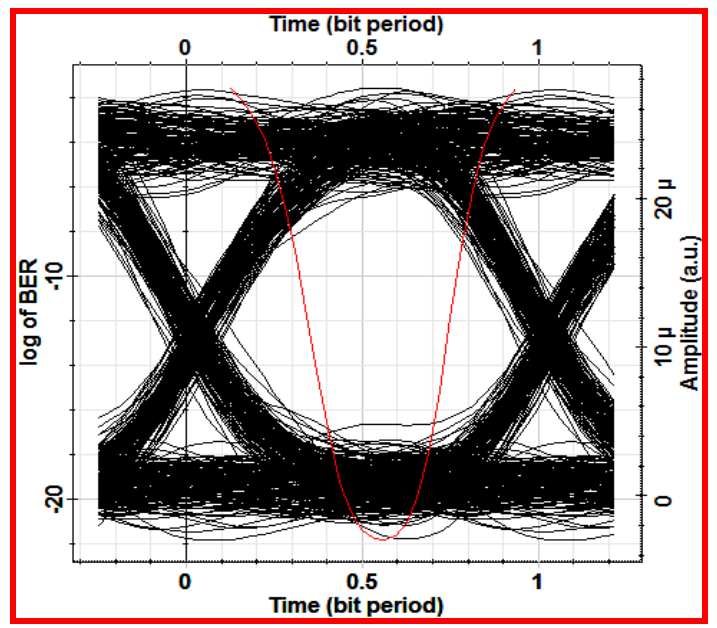

Fig.9.Eye diagram of downstream for the investigated tree topology of GPON

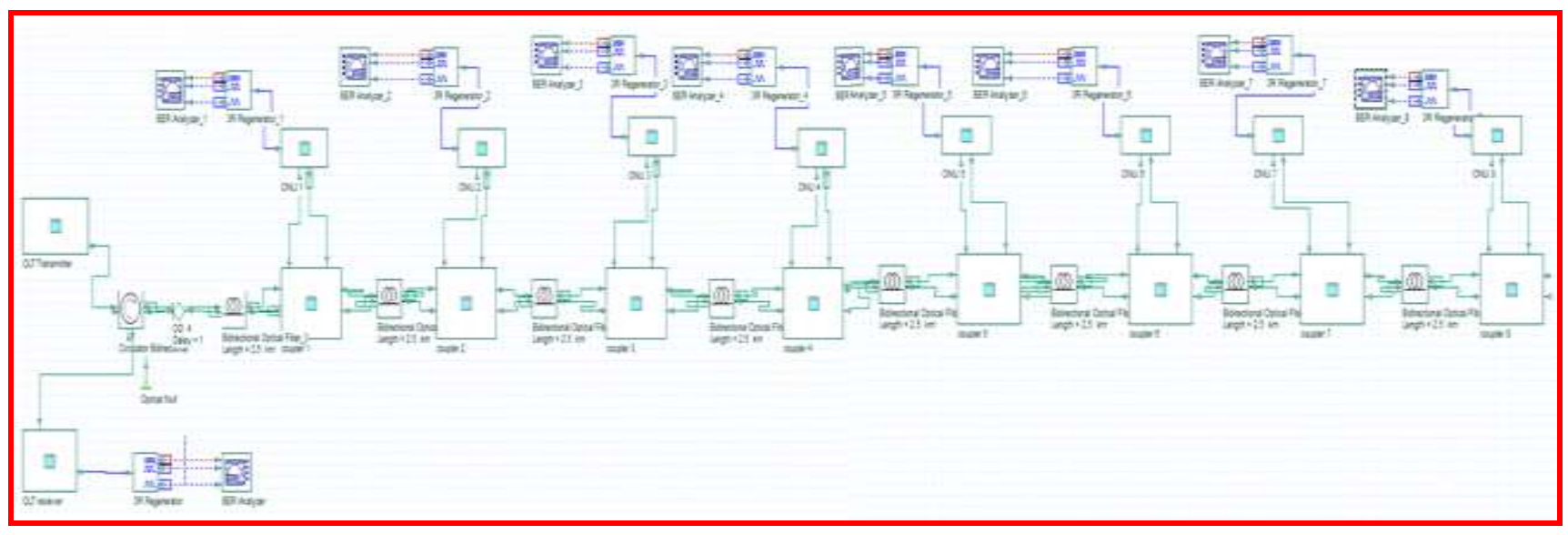

Fig.10. Structure of the investigated bus topology of GPON 

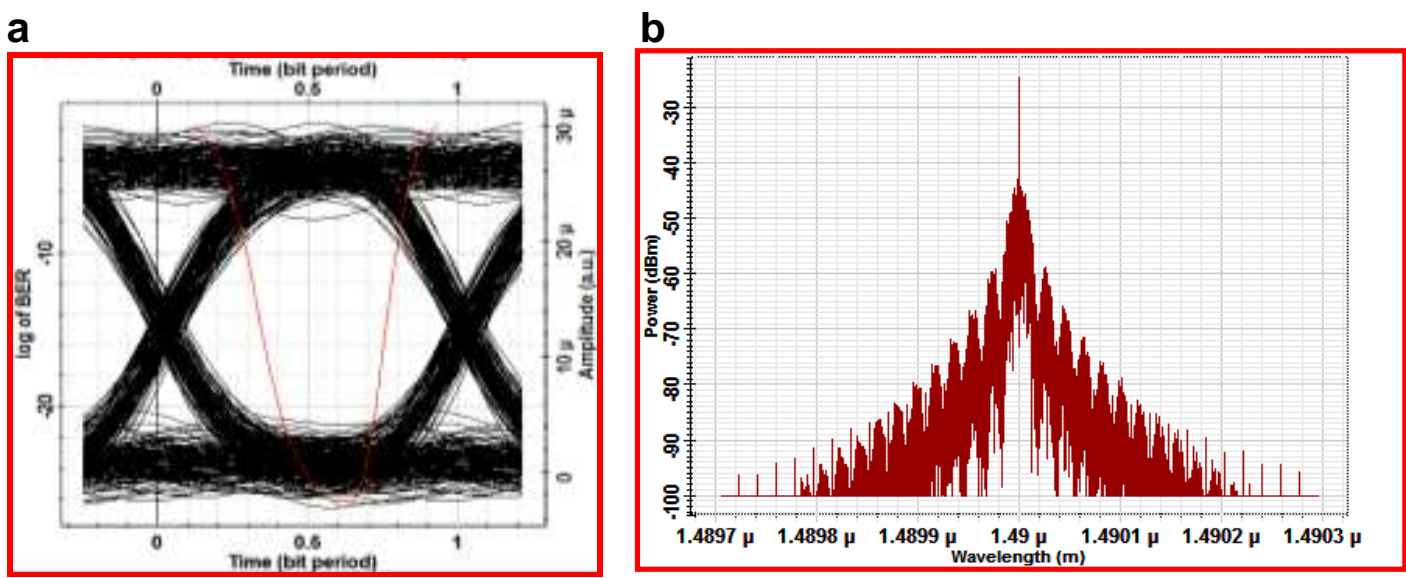

Fig.11.a) eye diagram for third ONU; b) optical spectrum

a

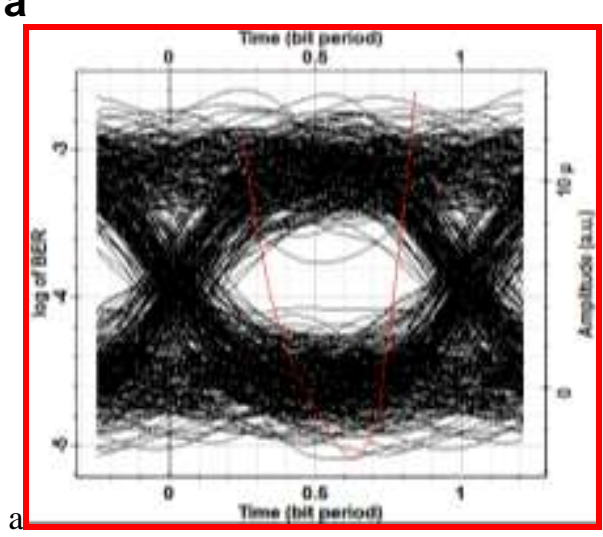

b

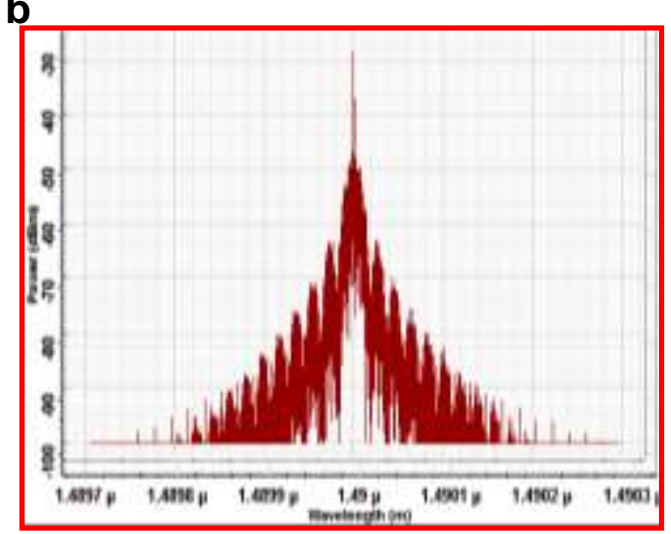

Fig.12. a) eye diagram for fourth ONU; b) optical spectrum

a

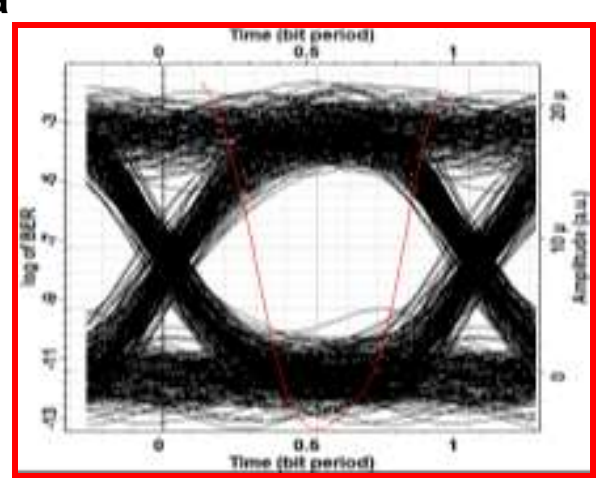

b

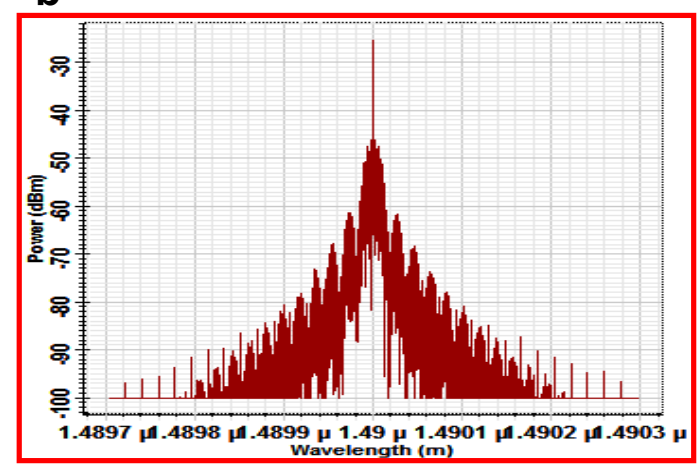

Fig.13.a) eye diagram for fourth ONU; b) optical spectrum 
a

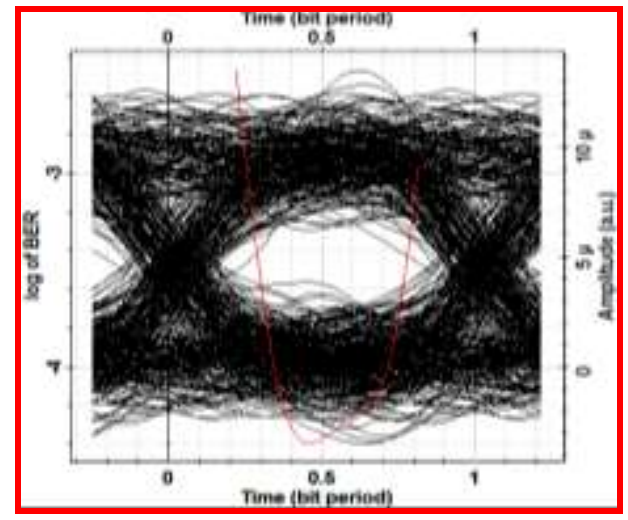

b

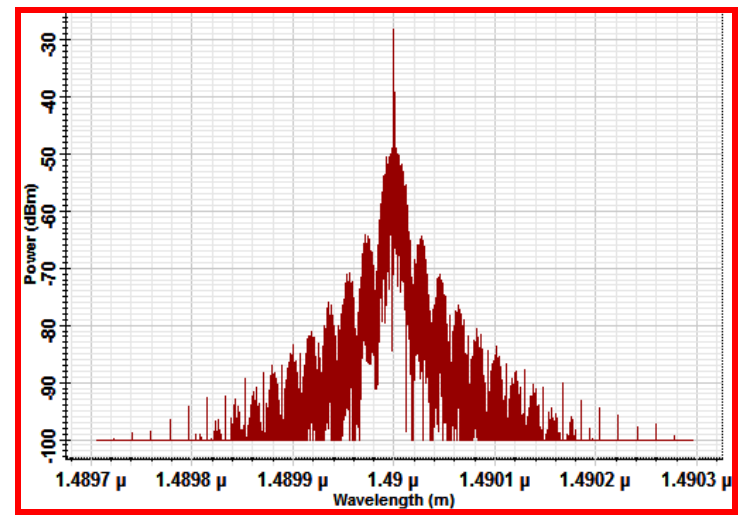

Fig.14. a) eye diagram for fifth ONU; b) optical spectrum

a

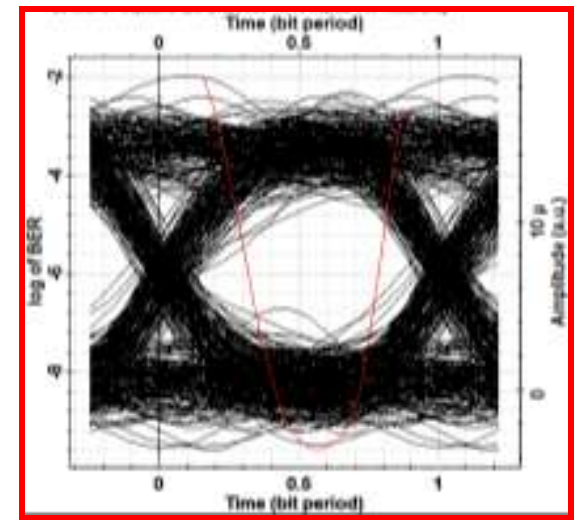

b

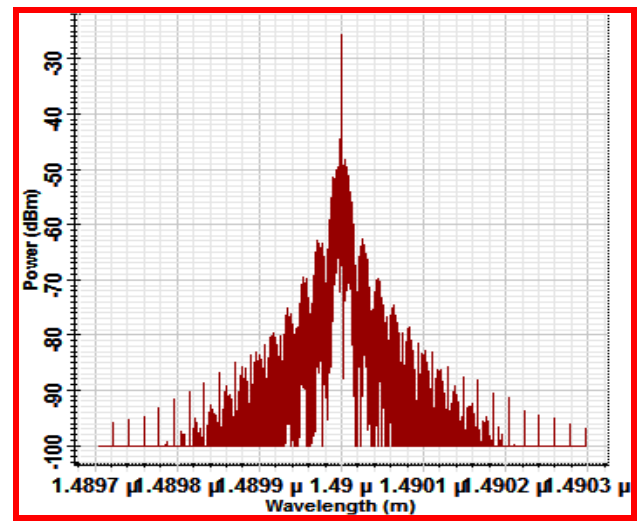

Fig.15.a) eye diagram for fifth ONU; b) optical spectrum

a

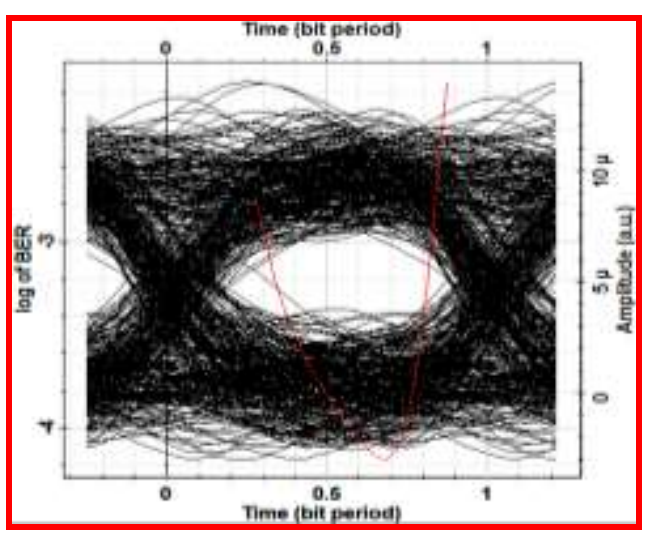

b

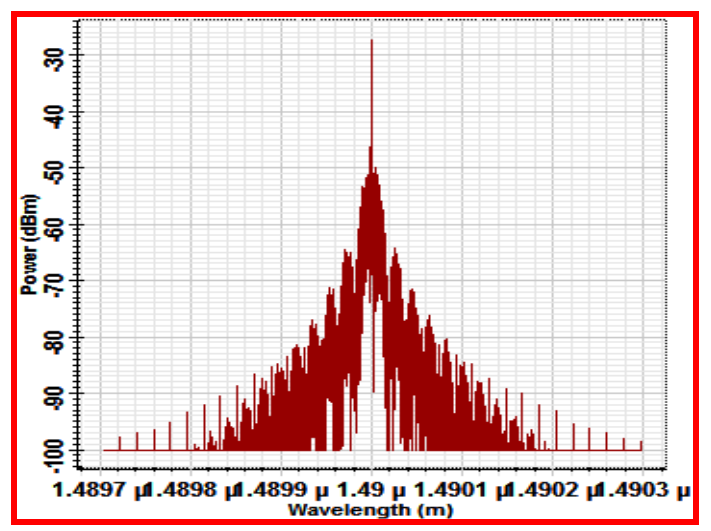

Fig.16. a) eye diagram for sixth ONU; b) optical spectrum 


\section{References}

[1] C. DeCusatis, "Handbook of fiber optic data communication: a practical guide to optical networking," Fourth ed London: Academic Press, 2013.

[2] M. Pradeep, B. Pavithra, R. Pooja, S. Parameswari, and M. Pandi, "A Survey of FTTH Elements Based on Broadband Access Network," Asian Journal of Applied Science and Technology (AJAST), vol. 1, pp. 54-59, 2017.

[3] H. S. Abbas and M. A. Gregory, "The next generation of passive optical networks: A review " Journal of Network and Computer Applications, vol. 67, pp. 53-74, 2016.

[4] L. A. Nair and G. Lakshmy, "Performance Analysis of Bus Topology in Fiber Optic Communication," International Journal of Computational Engineering Research, p. 51, 2015.

[5] J. Prat, "Next-generation FTTH passive optical networks," Springer Science+ Business Media B., vol. 5, 2008.

[6] S. Bindhaiq, A. S. M. Supa, N. Zulkifli, A. B. Mohammad, R. Q. Shaddad, M. A. Elmagzoub, and A. Faisal, "Recent development on time and wavelengthdivision multiplexed passive optical network (TWDM-PON) for next-generation passive optical network stage 2 (NG-PON2)," Optical Switching and Networking, vol. 15, pp. 53-66, 2015.

[7] C. F. Lam, Passive optical networks: principles and practice: Academic Press, 2011.

[8] G. Keiser, Optical fiber communications, fourth ed., 2010.

[9] S. Singh, "Performance investigation on DWDM optical ring network to increase the capacity with acceptable performance," Optik-International Journal for Light and Electron Optics, vol. 125, pp. 5750-5752, 2014.

[10] ITU-T, "Gigabit-capable Passive Optical Networks (GPON): Physical Media Dependent (PMD) layer specification," in G.984.2, , ed, 2003.

[11] M. Irfan, M. S. Qureshi, and S. Zafar, "Evaluation of advanced modulation formats using triple-play services in gpon based ftth," in Cloud Computing (ICCC), 2015 International Conference on, 2015, pp. 1-6. 